\title{
FREQUENCY OF STRESS HYPERGLYCEMIA AND MORTALITY IN PATIENTS WITH HYPERGLYCEMIA IN MEDICAL INTENSIVE CARE UNIT
}

\author{
Shahzeb Ahmed Satti, Abdul Latif Khattak, Abdul Moueed Tariq, Sultan Mehmood Majoka*, Arshad Naeem*, Rafi Ud Din \\ Combined Military Hospital Quetta/National University of Medical Sciences (NUMS) Pakistan, *Pak Emirates Military Hospital/National University of Medical \\ Sciences (NUMS) Rawalpindi Pakistan
}

\begin{abstract}
Objective: To assess the frequency of stress hyperglycemia and mortality in patients with hyperglycemia admitted in medical Intensive Care Unit.

Study Design: Cross-sectional study.

Place and Duration of Study: Medical Intensive Care Unit, Combined Military Hospital Quetta, from Nov 2018 to Jun 2019.

Methodology: A total of 150 adult patients of age between 18-80 years, of both genders, with Intensive Care Unit stay $>24$ hours, who were treated in medical Intensive Care Unit during study period, were included in the study. Those patients with duration of stay $<24$ hours, paediatric patients, surgical and pregnant patients and those who were on chronic steroid therapy and those who were given TPN and dextrose infusions were excluded. The blood sugar fasting was measured daily and blood sugar random was measured on admission and twice daily. The patients were segregated into three groups: Normoglycemia, Diabetes mellitus and Stress hyperglycaemia. The frequency of patients and outcome of patients in terms of death was observed in all groups.

Results: The mean age of study population was $55.02 \pm 18.14$ years, with $99(66 \%)$ were males while $51(34 \%)$ were females. Among study population 77 (51.3\%) had normoglycemia, 46 (30.7\%) had Diabetes Mellitus while 27 (18\%) had stress hyperglycaemia. Out of 77 patients with normoglycemia $10(12.9 \%)$ died, while number of deaths in patients with diabetes mellitus and stress hyperglycaemia was $21(45.6 \%)$ and $15(55.5 \%)$ respectively. The mean maximum blood glucose in those who survived and died was $214.39 \pm 100.69 \mathrm{mg} / \mathrm{dl}$ and $295.26 \pm 122.60 \mathrm{mg} / \mathrm{dl}$ respectively, which was significant with a $p$-value $<0.01$. Conclusion: This study showed that $18 \%$ patients had stress hyperglycemia with higher mean maximum blood glucose levels in those who died, as compared to who survived.
\end{abstract}

Keywords: Intensive care unit, Mortality, Stress hyperglycemia.

This is an Open Access article distributed under the terms of the Creative Commons Attribution License (https://creativecommons.org/licenses/by-nc/4.0/), which permits unrestricted use, distribution, and reproduction in any medium, provided the original work is properly cited.

\section{INTRODUCTION}

Patients with hyperglycemia are increasingly seen in intensive care units. This hyperglycemia can be because of preexisting diabetes mellitus with a poor control or it may be stress induced. The stress induced hyperglycemia is defined as random blood glucose levels $>200 \mathrm{mg} / \mathrm{dl}$ or fasting blood glucose $>126 \mathrm{mg} / \mathrm{dl}$ in patient with acute injury or illness without pre-existing diabetes mellitus ${ }^{1}$. It may resolve spontaneously after the acute illness is over. The term generally is used for those patients who do not have previous diabetes mellitus but patient with previously diagnosed diabetes mellitus may also develop stress induced hyperglycemias $^{2}$. This Stress induced hyperglycemia is not well studied. The stress hyperglycemia results in worst outcomes in ICU patients ${ }^{3}$. Although traditionally it is thought to be an adaptive response to acute illness but nowadays it is considered to be the cause of poor outcomes in ICU patients. In acute and critical illness,

Correspondence: Dr Sultan Mehmood Majoka, Classified Medical Specialist, Pak Emirates Military Hospital, Rawalpindi Pakistan

Received: 19 Sep 2019; revised received: 19 Apr 2020; accepted: 21 Apr 2020 various hormones get activated such as activation of hypothalamic pituitary axis, release of catecholamines, glucagon and growth hormones ${ }^{4}$. As a result, lipolysis of adipose tissue, proteolysis involving the skeletal muscles, hepatic gluconeogenesis and glycogenolysis may take place, resulting in increased glucose resistance. There are also many exogenous factors involved which can exacerbate this insulin resistance and hyperglycemia ${ }^{5}$. These factors include use of steroids, use of vasopressors and dextrose infusions. This severe hyperglycemia is a catabolic state with various effects. The increased blood sugar levels lead to glucosuria and osmotic diuresis resulting in loss of water and electrolytes. This causes dehydration, and hemodynamic compromise 6 . The Osmotic diuresis can cause hyponatremia which can be symptomatic. The hyperglycemia also results in poor wound healing7. It is not known whether the stress hyperglycemia itself causes damage or its just marker of severity of illness. The stress hyperglycemia, in previous studies was seen to be cause of increased deaths in patients admitted in ICUs ${ }^{8}$. The study was done to assess the frequency of stress hyperglycemia in our setup and association of 
hyperglycemia with mortality in patients admitted in intensive care units so that stress hyperglycemia may be identified as an independent risk factor for poor outcomes in critically ill patients and such patients may be treated with standard therapy to prevent poor outcome.

\section{METHODOLOGY}

It was cross-sectional study conducted at Medical Intensive Care Unit of Combined Military Hospital Quetta, from November 2018 to June 2019. The permission was sought from institution ethics review committee (ltr no.Trg-IRB-28-08/001). The sample size ( $\mathrm{n}=$ 150) was calculated with the help of WHO sample size calculator using a confidence level of $95 \%$, margin of error $5 \%$ and population portion of $12 \%{ }^{8}$. All the adult patients of both genders admitted in the ICU facility with age between 18-80 years and hospital stay more than 24 hours were included, while those patients with stay less than 24 hours, patients with hyperthyroidism, paediatric and surgical patients, pregnant females, patients with history of chronic steroid use and those who were given total parenteral nutrition and dextrose infusions were excluded from study. The patients were selected in the study by non-probability consecutive sampling. The informed written consent was obtained from the patients or from first degree relatives for the patients who were unable to give consent. The demographic data including age and gender were collected. The history was taken regarding previous established diagnosis of diabetes mellitus, hyperthyroidism and for chronic steroid use. Blood sugar random was measured on arrival in Intensive care unit (ICU) by glucometer and sample was also sent to hospital pathology lab. The patients were daily followed with their fasting and random blood glucose levels during their stay in ICU for maximum of 7 days. Their mean maximum and minimum blood glucose was measured along-with total stay in ICU.

The patients were classified into three groups: normoglycemia, hyperglycaemia with diabetes mellitus and stress hyperglycaemia. According to American Diabetes Association the normoglycemia is defined as fasting blood glucose (FBG) less than $100 \mathrm{mg} / \mathrm{dl}$ or 2 hour blood (2-hr) glucose less $140 \mathrm{mg} / \mathrm{dl}$, while prediabetes is defined as FBG between $100-125 \mathrm{mg} / \mathrm{dl}$ or 2-hr blood glucose between $140-200 \mathrm{mg} / \mathrm{dl}$ and the diabetes is defined as FBG more than $126 \mathrm{mg} / \mathrm{dl}$ or 2$\mathrm{hr}$ blood $>200 \mathrm{mg} / \mathrm{dl}^{9,10}$. The stress induced hyperglycemia is defined as random blood glucose levels $>200$ $\mathrm{mg} / \mathrm{dl}$ or fasting blood glucose $>126 \mathrm{mg} / \mathrm{dl}$ in patient with acute injury or illness without pre-existing diabetes mellitus ${ }^{1}$.

The analysis was done by statistical package for social science (SPSS) version 18 . The descriptive variables such as frequency and percentages of male and female patients were calculated. The mean and standard deviation for age and duration of stay in ICU was measured. The patients were divided into 3 categories on the basis of their glycemic control i.e. normoglycemia, hyperglycemia with previous diabetes mellitus and stress hyperglycemia. The frequency and percentage of the patients in each group was calculated. The frequency and percentages of different types of glycemic control in survivors and those who did not survive were calculated. The association of outcome with gender and hyperglycemia was assessed using chi square test. The mean maximum blood glucose level was measured in those who survived and died. The independent sample t-test was used to compare the means in both groups and $p$-value $<0.05$ was taken as significant.

\section{RESULTS}

Out of these 150 patients 99 (66\%) were males, while $51(34 \%)$ were females. The mean age and duration of stay in intensive unit is shown in table-I.

Among study population 77 (51.34\%) had normoglycemia, $46(30.7 \%)$ were having hyperglycemia with diabetes mellitus while 27 (18\%) had stress hyperglycaemia as shown in figure.

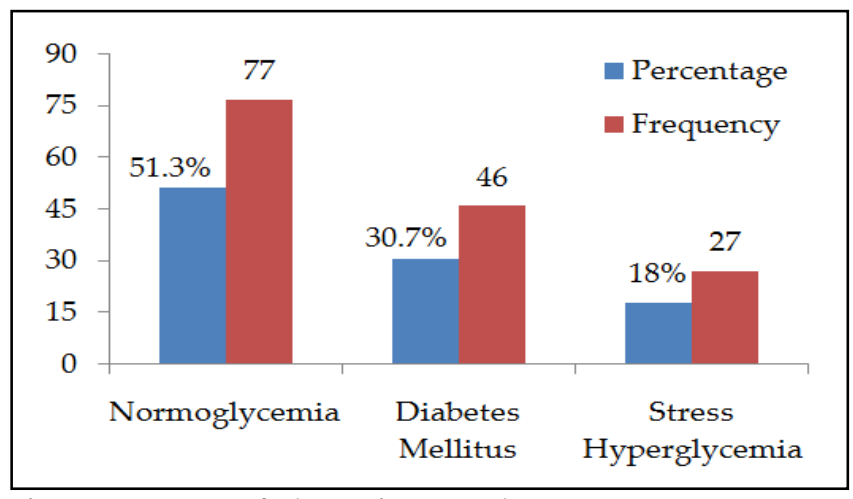

Figure-1: Types of glycemic control.

The frequency and percentages of different types of glycemic control in survivors and those who did not survive is shown in table-II.

The patients were divided into three groups on the basis of their mean blood glucose levels ie $<150$ $\mathrm{mg} / \mathrm{dl}, 150-300 \mathrm{mg} / \mathrm{dl}$ and $>300 \mathrm{mg} / \mathrm{dl}$ and number of deaths in each group was calculated. As the mean maximum blood glucose levels increased, the number 
of patients who could not survive also increased ( $10.4 \%$ versus $35.8 \%$ versus $47.5 \%$ ) depicting increased mortality associated with hyperglycemia in ICU patients, as shown in table-IV.

The mean maximum blood glucose in those who survived was lower than those who could not survive, which was significant with a $p$-value of $<0.01$ and there was no significant difference in the mean duration of stay in ICU in both groups as shown in table-III.

The association of outcome with gender and hyperglycemia was assessed using chi square test, which was not significant for gender but statistically significant for hyperglycemia ( $p$-value $<0.01$ ).

Table-I: Descriptive studies.

\begin{tabular}{|c|c|c|c|c|c|c|c|}
\hline \multicolumn{2}{|l|}{ Parameter } & $\mathbf{N}$ & \multicolumn{2}{|c|}{ Mean \pm SD } & \multicolumn{2}{|c|}{ Max. } & Min. \\
\hline \multicolumn{2}{|l|}{ Age (years) } & 150 & \multicolumn{2}{|c|}{$55.02 \pm 18.14$} & \multicolumn{2}{|c|}{80} & 18 \\
\hline \multicolumn{2}{|c|}{$\begin{array}{l}\text { Duration of Stay } \\
\text { in ICU (days) }\end{array}$} & 150 & \multicolumn{2}{|c|}{$4.81 \pm 2.94$} & \multicolumn{2}{|c|}{15} & 2 \\
\hline \multicolumn{8}{|c|}{ Table-II: Glycemic control and associated outcomes. } \\
\hline \multicolumn{3}{|c|}{$\begin{array}{l}\text { Type of Glycemic } \\
\text { Control }\end{array}$} & \multicolumn{2}{|c|}{ Survivors } & \multicolumn{3}{|c|}{$\begin{array}{c}\text { Non } \\
\text { Survivors }\end{array}$} \\
\hline \multicolumn{3}{|c|}{ Normoglycemia } & \multicolumn{2}{|c|}{$67(87.0 \%)$} & \multicolumn{3}{|c|}{$10(12.9 \%)$} \\
\hline \multicolumn{3}{|c|}{ Diabetes Mellitus } & \multicolumn{2}{|c|}{$25(45.3 \%)$} & \multicolumn{3}{|c|}{$21(45.6 \%)$} \\
\hline \multicolumn{3}{|c|}{ Stress Hyperglycaemia } & \multicolumn{2}{|c|}{$12(44.4 \%)$} & \multicolumn{3}{|c|}{$15(55.5 \%)$} \\
\hline \multirow{2}{*}{\multicolumn{2}{|c|}{ Outcome }} & \multirow{2}{*}{\multicolumn{2}{|c|}{$\begin{array}{r}\text { Me } \\
<150 \mathrm{mg} / \mathrm{dl}\end{array}$}} & & & & \\
\hline & & & & $150-300 \mathrm{mg} / \mathrm{dl}$ & \multicolumn{3}{|c|}{ l $>300 \mathrm{mg} / \mathrm{dl}$} \\
\hline \multicolumn{2}{|c|}{ Non survivors } & \multicolumn{2}{|c|}{$5(10.4 \%)$} & $22(35.48 \%$ & \multicolumn{3}{|c|}{$19(47.5 \%)$} \\
\hline \multicolumn{2}{|l|}{ Survivors } & $43(89$. & & $40(64.5 \%$ & \multicolumn{3}{|c|}{$21(52.5 \%)$} \\
\hline \multicolumn{8}{|c|}{$\begin{array}{l}\text { Table-III: Mean Maximum blood glucose and stay in ICU } \\
\text { among survivors \& non survivors. }\end{array}$} \\
\hline & \multicolumn{2}{|c|}{ Outcome } & $\mathbf{N}$ & \multicolumn{2}{|c|}{ Mean \pm SD } & & -value \\
\hline \multirow{2}{*}{$\begin{array}{l}\text { Maximum } \\
\text { Blood } \\
\text { Glucose } \\
(\mathrm{mg} / \mathrm{dl})\end{array}$} & & $\begin{array}{l}\text { Non } \\
\text { vivors }\end{array}$ & 46 & $\begin{array}{r}295.26 \\
122.6\end{array}$ & & & $<0.01$ \\
\hline & & rvivors & 104 & $\begin{array}{r}214.39 \\
100.6\end{array}$ & & & $<0.01$ \\
\hline $\begin{array}{l}\text { Stay in } \\
\text { ICU }\end{array}$ & & $\begin{array}{l}\text { Non } \\
\text { vivors }\end{array}$ & 37 & $5.41 \pm 3$ & & & $>0.05$ \\
\hline (days) & & rvivors & 73 & $4.55 \pm 2$ & & & $>0.05$ \\
\hline
\end{tabular}

\section{DISCUSSION}

Stress hyperglycaemia is increasingly being identified in patients with acute illness especially those admitted in intensive care units. The stress induced hyperglycaemia may represent the severity of illness and is associated with increased deaths in ICU patients. Our study showed the prevalence of stress hyperglycemia is our ICU was $18 \%$ which is comparable with results of previous studies. In a study done by Umpierrez and colleagues, the frequency of stress hyperglycemia was $12 \% 8$. The frequency of stress hyperglycaemia in ICU patients was found to be $5.7 \%$ in a study done in Iran in $2017^{11}$. The study done by
Godinjak et al, showed that the prevalence of stress hyperglycemia was about $19 \% 12$. In a study done in India by Jitendra Sharma et al, have shown that the prevalence of stress hyperglycemia was about $20.33 \%$ 13. Our study also showed that, more percentage of patients with stress hyperglycemia had deaths than those with previous diabetes consistent with previous studies. In the Iranian study published in 2017, the mortality rate in patients with stress hyperglycemia was $44.5 \%$, while our study revealed the mortality rate of $55.5 \%$. The mortality rate in patients with stress hyperglycemia in study done by Umpierrez and colleagues in USA was $16 \%$, while it was $1.7 \%$ in those with normoglycemia and $3 \%$ in those who had prior diabetes ${ }^{8}$. In a study done by Godinjak and colleagues showed that ,among patients admitted to ICU, stress induced hyperglycemia resulted in 3-fold increase in mortality $(31 \%)$ than patients with previous diabetes $(10 \%)$ or those having normal blood glucose levels $(11.3 \%)^{10}$. The mortality rate in our study was more than seen in previous studies. A study done by Krinseley et al, including different groups of severely ill patients in ICU, had shown that mean and maximum blood sugar levels were much higher in those who died, in comparison with those who survived, which was also depicted in our study. The patients who had mean blood glucose values $>300 \mathrm{mg} / \mathrm{dl}$ had a mortality of $42.5 \%{ }^{14}$. Our study also showed the similar results with mortality of $52.5 \%$ in those with Blood glucose levels were $>300 \mathrm{mg} / \mathrm{dl}$. Similarly in surgical patients there was increased risk of nosocomial infections such as pneumonias, sepsis and wound infections with hyperglycemia $^{15}$. The insulin therapy, in addition to decreasing mortality can also prevent many complications such as nosocomial infections, AKI, hepatic damage, which results in improving overall outcomes in critical patients. Whether it should be intensive insulin therapy or less strict glycemic control is still an ongoing debate ${ }^{16}$. Various societies have recommended various different guidelines for management of hyperglycemia in critical ill patients admitted in ICUs ${ }^{17}$. According to guidelines the American Diabetes Association (ADA), a target blood glucose levels between 7.7-9.9 mmol/L is recommended ${ }^{18}$.

In patients with severe sepsis, keeping blood sugar levels between 4.4-6.1 mmol/L did not resulted in a mortality benefit; instead it has caused more harmful effects, such as hypoglycemia ${ }^{19}$. Similarly if blood glucose remains in the range of $70-140 \mathrm{mg} / \mathrm{dL}$ for $>80 \%$ of time, it has shown to reduce mortality in non-diabetic critically ill ICU patients ${ }^{20}$. If glycemic variability 
is limited, it proves to be beneficial and decrease mortality. In a study done by Ali and colleagues, involving patients with sepsis, severe sepsis and septic shock, those patients with increased glycemic variability had more deaths ${ }^{21}$. The stress induced hyperglycemia in ICU patients poses a treatment challenge. The iatrogenic hypoglycemia should be avoided as it is also associated with increased mortality.

So, stress related hyperglycemia in critically ill patients is a risk factor associated with increased mortality. Further studies are required to compare the results in our setup. Studies are also required to compare various treatment protocols for controlling hyperglycemia in ICUs. There are slight limitations in our study. It did not exclude the patients who received steroids or vasopressors, as this may affect the insulin resistance and may lead to hyperglycemia.

\section{CONCLUSION}

This study showed that $18 \%$ had stress hyperglycemia in our study population. Those patients who were having increased mean blood glucose levels in medical ICU had increased mortality while length of stay in ICU did not affect mortality. An adequate glycemic control in critically ill patients can significantly improve outcomes.

\section{CONFLICT OF INTEREST}

This study has no conflict of interest to be declared by any author.

\section{REFERENCES}

1. Kamceva G, Vavlukis M, Kitanoski D. Newly diagnosed diabetes and stress glycaemia and its' association with acute coronary syndrome. Open Access Maced J Med Sci 2015; 3(4): 607-12.

2. Dungan KM, Braithwaite SS, Preiser JC. Stress hyperglycaemia. Lancet 2009; 373(9677): 1798-807.

3. El-Nagar MG, El-Raouf MA, El-Dien WS, Nooh MZ, Tawfiek AS. Study of hyperglycemia in critically ill patients and its impact on the outcome. Menoufia Med J 2018; 31(3): 935.

4. McCowen KC, Malhotra A, Bistrian BR. Stress-induced hyperglycemia. Critical care clinics. 2001;17(1):107-24.

5. Pakhetra R, Garg MK, Suryanarayana KM. Management of hyperglycemia in critical illness: review of targets and strategies. Med J Armed Forces India 2011; 67(1): 53-7.
6. Delaney MF, Zisman A, Kettyle WM. Diabetic ketoacidosis and hyperglycemic hyperosmolar nonketotic syndrome. EndocrinolMetabol Clin North Am 2000; 29(4): 683-705.

7. Kruse CR, Singh M, Sørensen JA, Eriksson E, Nuutila K. The effect of local hyperglycemia on skin cells in vitro and on wound healing in euglycemic rats. J Surg Res 2016; 206(2): 418-26.

8. Umpierrez GE, Isaacs SD, Bazargan N, You X, Thaler LM, Kitabchi AE. Hyperglycemia: an independent marker of in-hospital mortality in patients with undiagnosed diabetes. J Clin Endocrinol Metabol 2002; 87(3): 978-82.

9. American Diabetes Association. Classification and diagnosis of diabetes: standards of medical care in diabetes - 2019. Diabetes Care 2019; 42(Supplement 1): S13-28.

10. Yudkin JS. Prediabetes: are there problems with this label? yes, the label creates further problems! Diab Care 2016; 39(8): 1468-71.

11. Ala S, Salehifar E, Avan R, Ghasemishani S. Prevalence and management of stress hyperglycemia in critical care unit. J Mazandaran Uni Med Sci 2017; 26: 1-11.

12. Godinjak A, Iglica A, Burekovic A, Jusufovic S, Ajanovic A, Tancica I, et al. Hyperglycemia in critically ill patients: management and prognosis. Med Arch 2015; 69(3): 157-60.

13. Sharma J, Chittawar S, Maniram RS, Dubey TN, Singh A. Clinical and epidemiological study of stress hyperglycemia among medical intensive care unit patients in Central India. Indian J Endocrinol Metabol 2017; 21(1): 137-41.

14. Krinsley JS. Association between hyperglycemia and increased hospital mortality in a heterogeneous population of critically ill patients. Mayo Clin Proceed 2003; 78(12): 1471-78.

15. Kotagal M, Symons RG, Hirsch IB, Umpierrez GE, Dellinger EP, Farrokhi ET, et al. Perioperative hyperglycemia and risk of adverse events among patients with and without diabetes. Annals Surg 2015; 261(1): 97-100.

16. Kansagara D, Fu R, Freeman M, Wolf F, Helfand M. Clinical Guideline. Ann Intern Med 2011; 154(1): 268-82.

17. Martensson J, Egi M, Bellomo R. Chapter 79 - blood glucose control in critical care. In: Ronco C, Bellomo R, Kellum JA, Ricci Z, editors. Critical care nephrology (Third Edition). Philadelphia: Content Repository Only! 2019. p. 464-9.e2.

18. Executive summary: standards of medical care in diabetes-2012. Diabetes care 2012; 35(Suppl-1): S4-s10.

19. Brunkhorst FM, Engel C, Bloos F, Meier-Hellmann A, Ragaller $\mathrm{M}$, Weiler $\mathrm{N}$, et al. Intensive insulin therapy and pentastarch resuscitation in severe sepsis. New England J Med 2008; 358(2): 125-39.

20. Krinsley JS, Preiser JC. Time in blood glucose range 70 to 140 $\mathrm{mg} / \mathrm{dl}>80 \%$ is strongly associated with increased survival in non-diabetic critically ill adults. Critical Care 2015; 19(1): 179-82.

21. Ali NA, O'Brien JM, Dungan K, Phillips G, Marsh CB, Lemeshow $\mathrm{S}$, et al. Glucose variability and mortality in patients with sepsis. Critical Care Med 2008; 36(8): 2316-21. 